\title{
Why Knowledge of Student Financial Aid is Important to Orientation Professionals
}

\author{
Myron L. Pope
}

As professionals in student affairs, orientation personnel must emphasize the significance of programs and services to both the mission of the institution and to the development of students. Higher education has formatted student programming on the philosophy that it should front load programs. "Front loading" refers to a belief that student success and matriculation begins with programming for new students. Additionally, researchers supports that these students are most likely to be lost to attrition due to their inability to make a successful transition to college. As orientation programs are the very first aspect of programming for transitioning students, it is important that these programs provide a maximum level of service. One segment of this programming is financial aid. as the amount of a student financial aid award is a significant determinant in a student's decision to attend an institution, and therefore, it is important that orientation personnel have an understanding of the origins, philosophy, and current status of financial aid. This information is important for orientation personnel as they develop programs and promote a holistic view of student success, including how students pay for college.

To gain a perspective of student financial aid, orientation personnel should first understand the history of student financial assistance. Higher education has transformed greatly in regard to its democratization of college opportunities for its citizens in the last 150 years. Since the land grant college movement of the 1800 s, there have been several major phases of growth in higher education that have been a result of public policy. The land grant college movement was one of the first major efforts to provide public support for public higher education. However, it was not until Congress passed the G. I. Bill of Rights that the country first provided a substantial amount of support for individuals seeking access to college. This bill rewarded veterans returning from World War II, a majority of who otherwise would not have had a chance to pursue higher education, the opportunity to attend higher education. Despite this aggressive effort and other attempts that immediately followed, the government efforts to financially support its citizenry to attend higher education were futile. The controversies that inhibited the idea of federal support of higher education included civil rights issues, church-state controversies, and fear of federal control of education. Not until the National Defense Education Act of 1958, through the Higher Education Act of 1965, the Education Amendments of 1972, 1976, and 1980, and the Middle Income Student Assistance Act of 1978, was there a structure of financial assistance designed to make it possible for young men and women who needed financial assistance to go to college.

The philosophy of governmental student financial assistance beginning in 1965 focused on eliminating poverty by investing in education and health programs that

Myron L. Pope, EdD, is an Assistant Professor of Adult and Higher Education at the University of Oklahoma. His research interests focus primarily on the culture and environment of students in higher education settings. 
benefited the poor, eradicating barriers to economic opportunity through civil rights, and creating jobs for the poor prior to their entrance into the labor market. This approach centered on the concept of financial need, the difference between the student's educational expenses and the amount of money the family is expected to contribute. Based on this standardized formula established by the government for all participating postsecondary institutions, students are awarded a financial aid package consisting of one or more types of financial assistance, which includes grants, loans, and work-study. This stance contributed to the tremendous growth in higher education enrollment by Americans during the period since World War II. Today, one or more of these three forms of financial assistance to individuals provide an opportunity for over $50 \%$ of all students participating in higher education.

As student financial aid has witnessed growth over the past 50 years, so has student orientation. Orientation has existed to some degree since the very first students entered higher education because of the need to assist them in their transition to their new environment. Also, orientation has served to enhance student success in college. Despite this existence and growth, orientation's popularity has experienced its greatest successes during the last century. As student enrollment growth began to slow during the 1970s and 1980s, student satisfaction and retention became very significant issues to higher education administrators. Research during this period demonstrated that orientation contributed positively to both of these variables. Consequently, orientation personnel found themselves contributing to the economic stability of higher education. As admissions and higher education changed its focus to an enrollment management philosophy, orientation offices found themselves playing a significant role in promoting the goals of these efforts.

Orientation personnel, as part of the enrollment management process, must serve as advocates of change. These individuals have an opportunity to continue to promote the successes of the area to the rest of the team, including financial aid. The programs that are developed in orientation offices provide a combination of services, interactions, and programs that are beneficial to new students having either an immediate or long-term benefit. Research has consistently shown that attrition is most severe during the first year, so many administrators work to provide additional support to orientation personnel. As this was a significant victory for those who work in and support orientation programs, it is equally important to assess orientation programs periodically to ensure that these findings are still consistent and significant. Also, it is important through this assessment process to maximize student success by efficiently identifying and modifying personnel and services.

With higher education costs continuing to rise, students are doing more research and comparison shopping to find the school that is going to provide them with the most beneficial "cost" package. Sometimes their search continues through orientation programs where they are able to ask additional questions and obtain further details about their options. What they discover during this shopping could possibly be the determining factor in their decision to stay or move on to the next institution to continue the process until they find a substantial award. In many cases, their questions are directed toward orientation personnel instead of financial aid personnel due to their 
accessibility. Thus, orientation personnel need to be able to relay some level of knowledge of student financial aid.

Considering this same scenario, orientation personnel can serve as advocates for financial aid for students. This role is relevant in this period when many are critical of student financial aid. Critics suggest that the government's financial subsidization of higher education has failed the population for which it was originally designed, the poor. This is due in part to the shift from need based to merit based assistance, as well as the increased reliance on loans, a system that leaves many of the borrowers with a large debt burden upon leaving college. To assist this group of students, orientation personnel can provide accurate information during transition programming about financial management of student loans and possible alternatives.

Another area that needs to be resolved between orientation and financial aid is their difference in theoretical backgrounds. Financial aid is primarily driven by the theory of Total Quality Management (TQM) as opposed to student development theory. TQM is attentive to needs of the student as a customer. This approach includes having staff assigned to meet the needs of students at the appropriate times, processing applications and other forms in a timely manner, and reducing delivery of service time. Orientation personnel, whose area focuses on student development theory, can provide the necessary planning that will most effectively achieve student success by meshing the two theories. Even though it is important for orientation personnel to have some basic knowledge of financial aid, it is even more significant to have an effective and formal line of communication with the financial aid office on their campus. In establishing this relationship, orientation personnel are able to implement aspects of student development theory without jeopardizing the aspects that are important to the financial aid office.

The opportunities for collaboration and promotion of the efforts of the offices of orientation and financial aid are multiple. As the student population continues to change, as well as the ways in which the public supports higher education, it is important that orientation personnel work to ensure that the mission of their work and philosophy is maintained. This process also entails that orientation personnel continue to assist financial aid in their efforts to enlighten students about financial assistance. Only through a better understanding of the philosophy and operations of student financial aid by orientation personnel can this goal be achieved. 